\title{
11
}

\section{Attracting and Retaining International Migrants: A Key Issue in Developing Northern Australia}

\author{
Linda Rosenman, Kate Golebiowska, Andrew Taylor, Petra T. \\ Buergelt, Hannah Payer, Huw Brokensha, Jan Salmon, Alicia \\ Boyle, Kerstin K. Zander and Pawinee Yuhun
}

\section{Introduction}

Reviews and enquiries into the development of Northern Australia have identified the small resident population as a key issue limiting future economic and social development: 'The small size of the population of Northern Australia, and its wide dispersal outside the handful of major centres ... is perhaps the key impediment to be overcome [in development planning]' (Joint Select Committee on Northern Australia, 2014, p. 109).

Ambitious plans for economic expansion are limited by labour shortages due to difficulties in recruiting skilled workers and high staff turnover. These factors not only increase recruitment, relocation and training costs, but also negatively impact business performance, productivity, profitability and growth. Companies may be unable to pursue market opportunities or have to cancel or delay strategic investments because of labour constraints. In key service areas such as health and education, high staff turnover has negative impacts on service delivery and client outcomes. Small populations and high turnover restrict the development of thriving communities and services that attract and retain workers and families. 
Despite the fact that Australia is an immigrant nation, with almost 30 per cent of the population born overseas, relatively little attention has been given to immigration as a key strategy for building a sustainable workforce and economically viable communities for Northern Australia. On a national scale, most of the research on immigration to regions has focused on southern parts of Australia (e.g. Taylor \& Stanovic, 2005; Flanagan, 2007; Piper \& Associates, 2007, 2008, 2009; Hugo, 2008; McDonald et al., 2008; Boese, 2015). This chapter complements this research. It also aims to better embed studies of immigration to Northern Australia conducted by researchers based in the north into the national body of knowledge. This chapter focuses on attracting and retaining immigrants and the ways they contribute to the development of economic and social capital.

We start with an analysis of the census data on recent (2011-16) and longer-term immigrants (those who arrived prior to 2011) to Northern Australia to develop a profile of immigrants to the north. This is a novel and ambitious approach that required more work 'behind the scenes' compared to the usual approach of analysing the census data for an entire state or territory, which is unsuitable for this study due to the definition of Northern Australia. We then review research on immigration and immigrants to regional areas, particularly in Northern Australia, that addresses key factors identified in attracting and retaining immigrants:

- employment and business opportunities

- family, psychosocial social and cultural connectedness

- place characteristics of Northern Australia.

Based on research on specific occupational groups that rely heavily on immigrants in Northern Australia, we conclude with identifying some of the strategies that may assist in attracting and retaining immigrants as workers and community members. This research was predominantly carried out in the Northern Territory (NT). 


\section{A Demographic and Socioeconomic Profile of International Migrants Living in 'the North'}

To provide a profile of the demographic and socioeconomic characteristics of overseas-born residents living in Northern Australia, we extrapolated custom tables from the 2016 Census. We compared and contrasted the profiles of overseas-born residents living in Northern Australia to those living in the rest of Australia. We also compared recent arrivals (those who arrived from 2011-16) to longer-term overseas-born residents (those who arrived prior to 2011) to identify changes and differences in migration patterns and characteristics.

\section{Size, Distribution and Sources}

In 2016, overseas-born residents comprised 17 per cent of the population of Northern Australia, lower than for the rest of Australia (29 per cent). Twenty-five per cent of overseas-born residents were new arrivals, higher than the average for the rest of Australia (22 per cent). The distribution of overseas-born residents is very city centric. High proportions, around 40 per cent, of the population are found in the suburbs and centres of the two largest cities of Northern Australia (Darwin and Cairns), including Wagaman (NT), Brinkin-Nakara (NT), Cairns City (Queensland), Coconut Grove (NT) and Darwin City (NT).

Table 11.1 shows the top five source countries and regions for overseasborn residents of Northern Australia. Northern Australia differs from the rest of Australia in that its immigrant share from New Zealand (17 per cent compared to 8 per cent) and Maritime Southeast Asia (13 per cent compared to 8 per cent) is higher, but its immigrant share from Southern Asia is lower (9 per cent compared to 12 per cent).

However, countries and regions of origin for overseas-born residents in Northern Australia appear to be changing markedly with large differences between those who arrived before 2011 (long-term residents) compared to those arriving after 2011 (recent arrivals). While the share of migrants from New Zealand and United Kingdom has declined, more Asian-born immigrants are now choosing to live in Northern Australia. 
Table 11.1: Main sources for overseas-born residents including longterm residents versus new arrivals (per cent).

\begin{tabular}{|l|c|c|c|c|}
\hline \multirow{2}{*}{ Source country/region } & \multicolumn{2}{|c|}{ All of Australia } & \multicolumn{2}{c|}{ Northern Australia } \\
\cline { 2 - 5 } & $\begin{array}{c}\text { Northern } \\
\text { Australia }\end{array}$ & $\begin{array}{c}\text { Rest of } \\
\text { Australia }\end{array}$ & $\begin{array}{c}\text { Arrived } \\
\text { before 2011 }\end{array}$ & $\begin{array}{c}\text { Arrived } \\
\text { after 2011 }\end{array}$ \\
\hline United Kingdom & 19.5 & 17.6 & 22.8 & 10.3 \\
\hline New Zealand & 16.6 & 8.2 & 17.8 & 12.8 \\
\hline Maritime Southeast Asia & 12.6 & 8.2 & 11.1 & 17.3 \\
\hline Southern Asia & 8.7 & 12.0 & 6.6 & 15.6 \\
\hline Southern and East Africa & 6.3 & 4.6 & 6.6 & 6.0 \\
\hline
\end{tabular}

Note: Maritime Southeast Asia includes Brunei Darussalam, Indonesia, Malaysia, Philippines, Singapore and Timor-Leste. Southern Asia comprises Bangladesh, Bhutan, India, the Maldives, Nepal, Pakistan and Sri Lanka.

Source: Census data extracted from Australian Bureau of Statistics (ABS, 2016) using ABS Table Builder software.

\section{Personal and Family Characteristics}

The age profile for overseas-born residents of Northern Australia is strikingly different to residents born in Australia (see Figure 11.1), with the overseas-born population being generally older and the majority being over 25 years old. This is primarily the result of skilled migration programs encouraging settlement of people of working age and with appropriate qualifications and experience.

In terms of marital status, a greater proportion of overseas-born residents in Northern Australia were in a de facto relationship (13 per cent) compared to those in the rest of Australia (8 per cent). Fewer overseas-born residents in Northern Australia (53 per cent) were married compared to married, overseas-born residents in the rest of Australia (57 per cent). 


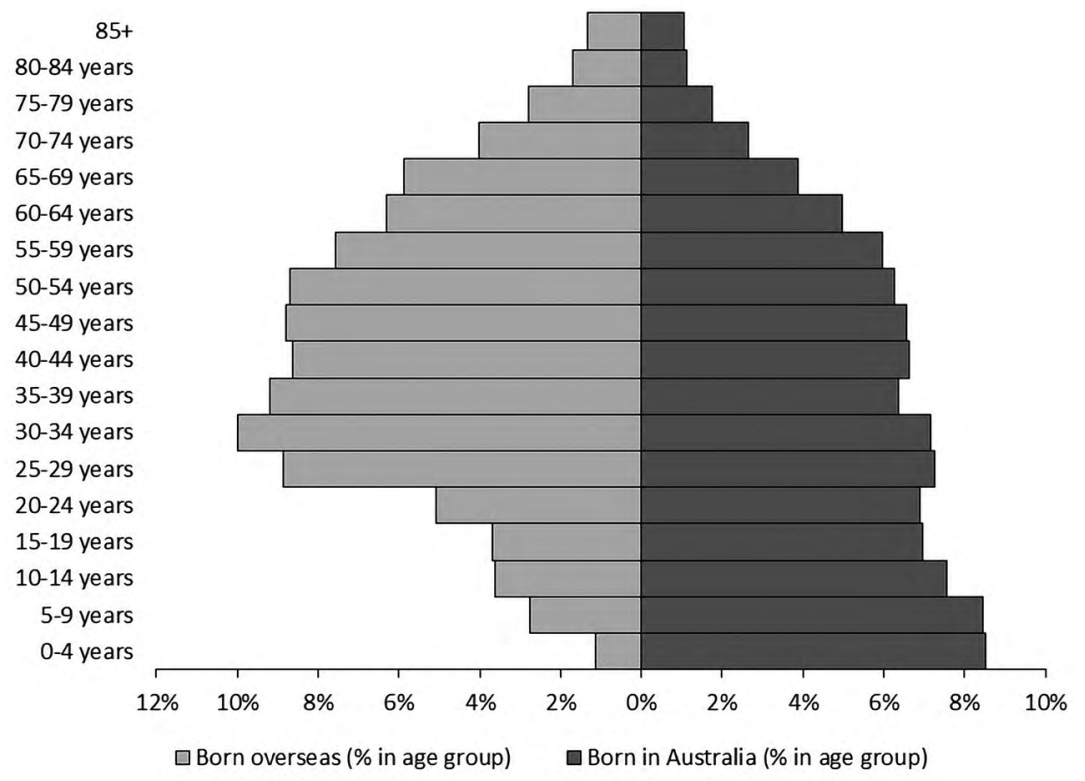

Figure 11.1: Age profile for Northern Australia residents born overseas and in Australia (2016).

Source: Census data extracted from ABS (2016) using ABS Table Builder software.

\section{Qualifications and Workforce Indicators}

A lower proportion of Northern Australian overseas-born residents with post-school qualifications ( 45 per cent) held a bachelor degree or higher qualification compared to overseas-born residents elsewhere in Australia (56 per cent). However, certificate-level qualifications were more prominent in the north. With the increase in migration under the skilled migration streams, a much larger proportion of recent arrivals (59 per cent) to Northern Australia held a bachelor or higher-level qualification than long-term overseas-born residents (41 per cent).

Compared to long-term overseas-born residents, a lower proportion of recently arrived immigrants worked in professional, managerial or clerical occupations in 2016, while higher proportions worked as labourers and community and personal service workers (see Figure 11.2). 


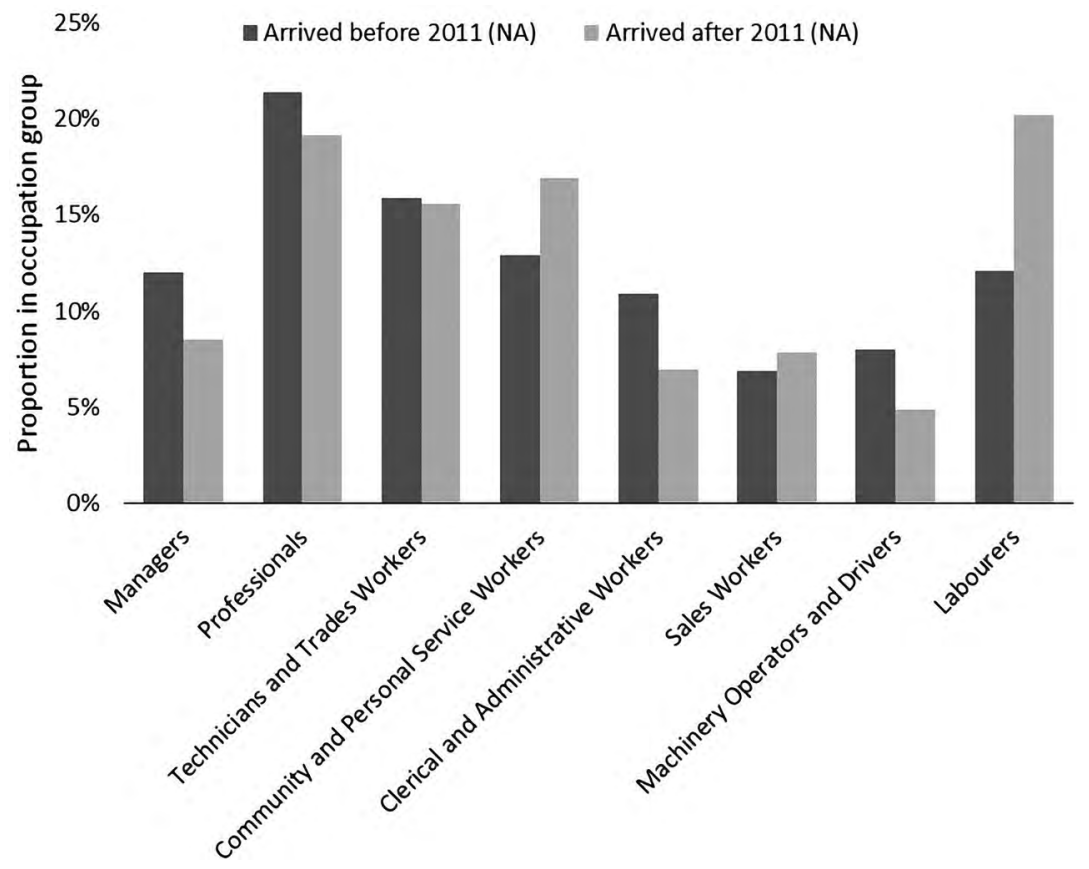

Figure 11.2: Occupations of employed long-term overseas-born residents and recent arrivals in Northern Australia (2016).

Note: NA = Northern Australia.

Source: Census data extracted from ABS (2016) using ABS Table Builder software.

The main industries of employment in 2016 for overseas-born residents in Australia were health care and social assistance followed by accommodation and food services (see Table 11.2). For recent arrivals, both industries are prominent employers, while a higher proportion of long-term overseasborn residents are employed in public administration and safety and education and training. Mining is a comparatively more important employer in Northern Australia, while manufacturing is more prominent in the rest of Australia.

Incomes of overseas-born residents in Northern Australia were markedly higher than those in the rest of Australia in 2016. For example, 39 per cent of overseas-born residents in Northern Australia stated they earned $A \$ 1,000$ per week or more compared to 32 per cent in the rest of Australia (see Figure 11.3). A large proportion of recent arrivals (18 per cent) stated they usually earned no income at all. 
Table 11.2: Industry of employment for overseas-born residents in 2016 (per cent).

\begin{tabular}{|c|c|c|c|c|}
\hline $\begin{array}{l}\text { Industry of } \\
\text { employment }\end{array}$ & $\begin{array}{l}\text { Northern } \\
\text { Australia }\end{array}$ & $\begin{array}{c}\text { Rest of } \\
\text { Australia }\end{array}$ & $\begin{array}{c}\text { Northern Australia } \\
\text { long-term } \\
\text { overseas-born } \\
\text { residents }\end{array}$ & $\begin{array}{c}\text { Northern } \\
\text { Australia recent } \\
\text { arrivals }\end{array}$ \\
\hline $\begin{array}{l}\text { Health care and } \\
\text { social assistance }\end{array}$ & 16.5 & 15.3 & 16.7 & 16.0 \\
\hline $\begin{array}{l}\text { Accommodation } \\
\text { and food services }\end{array}$ & 12.9 & 8.6 & 10.3 & 21.3 \\
\hline $\begin{array}{l}\text { Public } \\
\text { administration and } \\
\text { safety }\end{array}$ & 8.1 & 5.2 & 9.1 & 4.8 \\
\hline Retail trade & 7.8 & 8.8 & 7.7 & 8.1 \\
\hline $\begin{array}{l}\text { Education and } \\
\text { training }\end{array}$ & 7.8 & 7.4 & 8.6 & 5.2 \\
\hline Construction & 7.3 & 7.2 & 7.6 & 6.4 \\
\hline Mining & 6.6 & 1.2 & 7.2 & 4.8 \\
\hline $\begin{array}{l}\text { Transport, postal } \\
\text { and warehousing }\end{array}$ & 5.4 & 5.5 & 5.8 & 3.9 \\
\hline $\begin{array}{l}\text { Administrative and } \\
\text { support services }\end{array}$ & 4.6 & 4.5 & 4.3 & 5.6 \\
\hline $\begin{array}{l}\text { Professional, } \\
\text { scientific and } \\
\text { technical services }\end{array}$ & 4.5 & 9.3 & 4.6 & 4.3 \\
\hline Manufacturing & 4.1 & 8.0 & 4.1 & 4.3 \\
\hline Other services & 3.5 & 3.7 & 3.5 & 3.6 \\
\hline $\begin{array}{l}\text { Agriculture, forestry } \\
\text { and fishing }\end{array}$ & 3.3 & 1.3 & 2.7 & 5.1 \\
\hline Wholesale trade & 1.8 & 3.4 & 1.8 & 1.7 \\
\hline $\begin{array}{l}\text { Rental, hiring and } \\
\text { real estate services }\end{array}$ & 1.5 & 1.7 & 1.6 & 1.5 \\
\hline $\begin{array}{l}\text { Arts and recreation } \\
\text { services }\end{array}$ & 1.4 & 1.3 & 1.4 & 1.6 \\
\hline $\begin{array}{l}\text { Electricity, gas, } \\
\text { water and waste } \\
\text { services }\end{array}$ & 1.1 & 0.9 & 1.2 & 0.7 \\
\hline $\begin{array}{l}\text { Financial and } \\
\text { insurance services }\end{array}$ & 1.0 & 4.7 & 1.0 & 0.7 \\
\hline $\begin{array}{l}\text { Information } \\
\text { media and } \\
\text { telecommunications }\end{array}$ & 0.7 & 2.0 & 0.8 & 0.5 \\
\hline
\end{tabular}

Source: Census data extracted from ABS (2016) using ABS Table Builder software. 


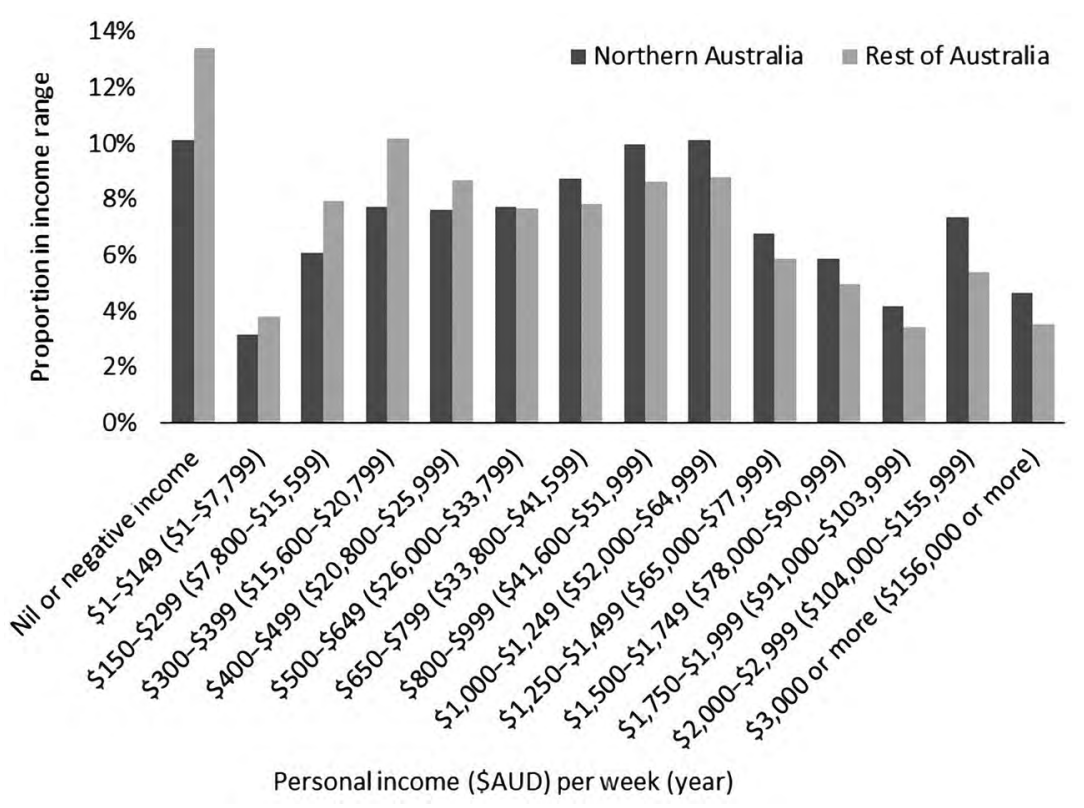

Figure 11.3: Weekly income profiles for employed overseas-born residents in Australia (2016).

Source: Census data extracted from ABS (2016) using ABS Table Builder software.

\section{Turnover and Retention}

It is possible to approximate interstate migration turnover rates and net interstate migration numbers for overseas-born residents by examining movements into and out of Northern Australia between 2011 and 2016. For Northern Australia, gross interstate turnover for overseas-born residents was more than double the turnover for Australian-born residents ( 4.8 per cent and 1.4 per cent respectively), indicating overseas-born residents of Northern Australia are more mobile. Unfortunately, it is not possible to differentiate whether the overseas-born residents of Northern Australia who leave move within Australia, leave Australia to step-migrate to another country or return to residing overseas.

Net interstate migration suggests that there has been a net outflow of overseas-born residents from Northern Australia, which from 2011-16 was equivalent to approximately -2.5 per cent of the 2016 overseasborn population of Northern Australia. Net migration was negative for both males and females (around $-1,000$ males and $-3,500$ females). 
The age profiles for net interstate migration of overseas-born residents (see Figure 11.4) reveal a predominantly net negative pattern for both males and females with the exception of males of working age (25-39 and 50-54 years old) and females aged between 25-29 years old. A net loss of children and especially of teenagers incorporates movements to attend secondary and tertiary educational institutions (often with parents), while the net loss of older migrants parallels that of the general population who tend to leave Northern Australia once they retire. Collectively, these data suggest that employment is the key driver of movements into the region. The range of reasons for leaving the region is more diverse.

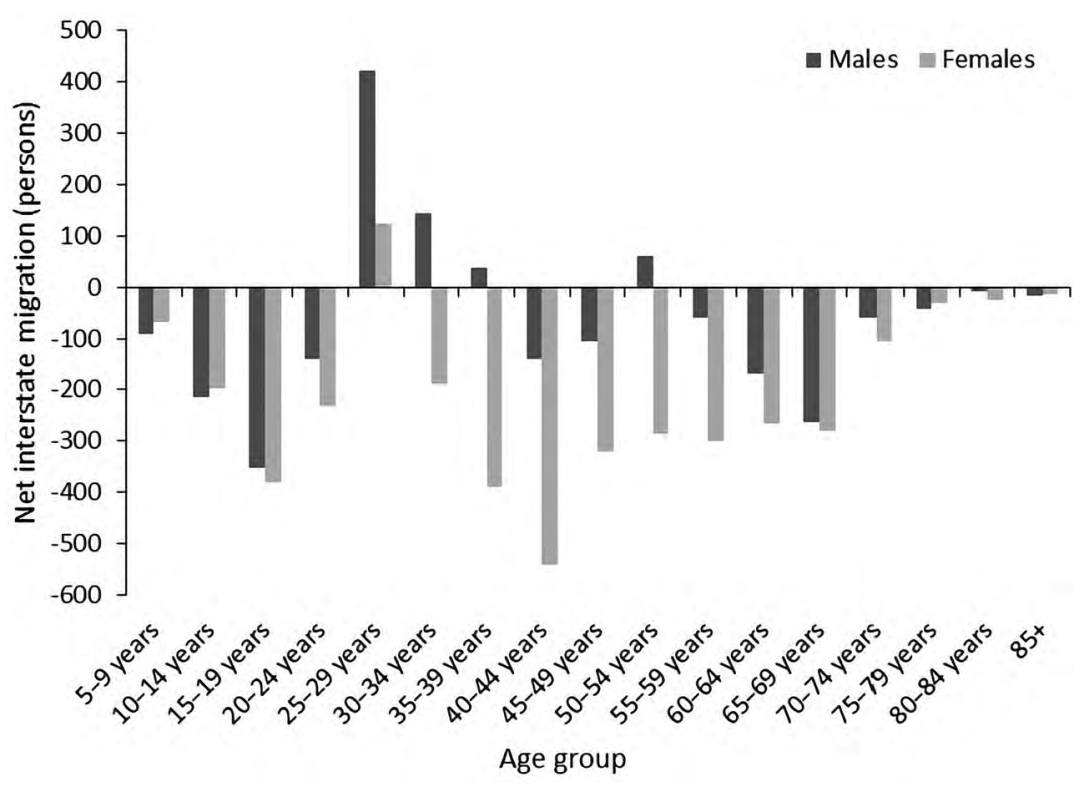

Figure 11.4: Overseas-born net interstate migration into Northern Australia by age and gender (2011-16).

Note: These data show the net result of subtracting overseas-born residents of Australia who lived in Northern Australia and then moved to the rest of Australia (negative figures) from those who lived in the rest of Australia and moved to Northern Australia during the period 2011-16 (positive figures).

Source: Census data extracted from ABS (2016) using ABS Table Builder software. 


\section{Employment and Business Opportunities}

The availability of a long-term job, better job or more suitable job for immigrants or their family members and business opportunities fundamentally influence the decisions to settle and remain in a particular area (Griffiths et al., 2010).

Currently, the majority of immigrants to Australia enter on skilled migration visas. Regional and state-sponsored programs in particular aim to attract and retain skilled immigrants to regional areas outside the southern capitals. Skilled migrants made up 58.3 per cent of total immigrants to the NT in 2011-12 and almost 40 per cent in Queensland (DIBP, 2013a). The most recent state and territory statistics reveal that these grew to 71 per cent in the NT and 63.2 per cent in Queensland in 2013-14 (DIBP, 2014). In recent years, regional and state-sponsored programs have driven the growth of skilled migration to the NT (Golebiowska, 2015).

The social and ethnic makeup of immigrant groups is changing. This is the case in regional Australia with growing numbers of immigrants from Asia, particularly the Indian subcontinent and the Philippines (Taylor et al., 2014). These immigrants are highly skilled and contribute significantly to the workforce, particularly in areas such as health and community services where it is difficult to attract and retain workers. Retaining these skilled immigrants and their families within regional areas and within their occupations reduces the costs of employee turnover and provides greater population stability.

\section{General Observations from Recent Studies}

Taylor et al. (2014) surveyed 400 recent skilled immigrants in the NT, who arrived under regional migration programs, to assess rates of retention in sponsored occupations. They found that regional skilled migration schemes are delivering positive labour market outcomes and relatively high residential retention rates among this immigrant cohort to the NT. The primary applicants as well as their (employed) partners were helping to address skills and labour shortages, particularly in health care and social services and accommodation and food services. Most participants intended to permanently settle in the NT, with 89 per cent 
of respondents still resident after initial settlement and 80 per cent of respondents stating an intention to remain. Job opportunities were the prime reason for intending to stay.

These results are consistent with Griffiths et al. (2010) who interviewed 110 immigrants, 26 employers and 15 government officials in regional Australia. Their study focused on four regional areas, three of which were in Northern Australia (Darwin, Mt Isa and Karratha) as were over 90 per cent of the respondents. They identified that:

Employment factors clearly played a central role in the settlement decision for many skilled migrants ... Availability of employment and business opportunities are fundamental factors in influencing decisions to settle and remain in a particular regional area. A high proportion of skilled migrants who ... reported settlement difficulty attribute[d] their difficulty to trouble in finding a job. Long-term employment opportunities for skilled migrants are crucial to the future of migration to regional areas. (Griffiths et al., 2010, pp. 5-6, 8)

State and regional skilled migration programs seem effective in attracting migrants and are a major opportunity to address skills shortages in Northern Australia. However, there is evidence that the potential contribution of immigrants may be under-utilised. While they have a higher employment rate in the NT (75 per cent) than Australian-born residents (67 per cent), many seem to be underemployed. For example, 47.3 per cent of permanent visa holders who arrived in 1997-2007 held overseas qualifications suitable for professional-level jobs, but only 28.3 per cent of those performed such jobs at the time of the 2006 Census and 42 per cent were employed in lower and unskilled occupations (Golebiowska, 2009, pp. 4, 6). This supports the previously discussed qualifications and workforce indicators findings and suggests that underutilisation of qualifications and skills is an established pattern.

Buergelt (2011) found that recognition of overseas qualifications and experience and under-utilisation of skills can be major hurdles to attracting and retaining immigrants. She identified that under-utilisation of immigrants' skills is due to several factors including the processes professional bodies put in place for gaining recognition of qualifications and/or experience (e.g. under-valuing of overseas qualifications or prior experience, requirements to re-sit exams despite years of work experience, high costs and long processing times) and negative perceptions by 
employers (e.g. uncertainty regarding skill levels, lack of Australianspecific knowledge in area of work, language issues including professional terminology, managing cross-cultural issues, and possibly fear of being outperformed due to having lower qualifications and less experience). This research suggests that it is crucial to identify the specific individual and contextual factors that influence under-employment among immigrants in Northern Australia to design effective strategies that ensure that the skills immigrants bring when they migrate are fully utilised.

\section{Observations from Recent Workforce-specific Studies}

Several of the challenges identified are evident in research on employment and mobility of nursing professionals in the NT (Garnett et al., 2008). ${ }^{1}$ Garnett et al. (2008) interviewed overseas-qualified professionals because they would have had to have deal with issues of foreign qualifications recognition and the transfer of their knowledge and skills in the Australian health context. The study revealed that in the 2001-06 intercensal period, the NT recorded a proportional decrease of nursing professionals born in the United Kingdom and New Zealand and a simultaneous increase in the share of nursing professionals born elsewhere, in particular in the Philippines and India. For health services in the NT, this requires dealing with greater variances in the levels of education in the future.

Garnett et al.'s (2008) survey results revealed that the skills of some overseas-qualified nursing professionals are under-utilised, although this needs to be seen in the context of their transferability to the Australian context. Higher proportions of overseas-qualified immigrants are qualified to work in critical care/emergency ( 4.6 per cent difference), mixed medical/surgical (15.8 per cent difference), medical (16.5 per cent difference) and surgical (15.5 per cent difference) areas than are actually working in them. Managers expressed reservations about the ability of some overseas-qualified nurses to work at full capacity and independently soon after arrival due to lack of familiarity with Australian medical terminology and variances in clinical skills. However, they agreed that

1 In this study, a survey questionnaire was distributed to Australian and overseas-qualified professionals. Responses were received from 1,006 individuals of whom 127 were overseas qualified. Semi-structured interviews were conducted with some individuals from the latter group. Managers of overseas-qualified professionals in public hospitals were also interviewed. 
although considerable initial support was required, the benefits were that overseas-qualified nurses tended to have a lower turnover rate than their Australian-qualified counterparts.

Data from the Department of Immigration and Citizenship (DIAC) ${ }^{2}$ revealed that between 1996 and 2007, employer-linked permanent visas granted to registered nurses in the NT were the most common immigration avenue (surpassing skilled independent migration and family-linked skilled migration) (Garnett et al., 2008). DIAC data also revealed that the number of registered nurses granted employer-nominated temporary skilled visas (formerly 457 visas) in 2006-07 was nearly double the number of employer-nominated permanent skilled visas granted in this period to registered nurses destined for the NT ( 80 versus 46 respectively). The high volume of 457 visas granted is consistent with the information obtained from interviews with nurse managers who added that nurses would typically convert to permanent skilled visas once they were eligible (Garnett et al., 2008). Despite annual fluctuations in numbers from 130 to 40 , between 2009-10 and 2012-13 registered nurses were the top occupation nominated for 457 visas in the NT (primary applicants only) (DIAC, 2011; DIBP, 2013b). Similar occupation-level data are not immediately available for permanent migration to the NT.

Garnett et al.'s (2008) analysis of immigrant age distribution and period of arrival data (from the 2006 Census) showed that the NT nursing workforce had a higher percentage of recently arrived overseas-born professionals aged 20-39 years old than Australia as a whole. These immigrants were probably less experienced than the rest of the immigrant workforce, but their longer working lifespan meant that if they gained the necessary experience and decided to remain in the NT, they could form the core of a future nursing workforce. This, in turn, could provide some continuity of service, which is a challenge due to a high turnover of the Australian-born nursing workforce in the NT.

Nurses come to the NT for a number of social and economic reasons. The three most common reasons for Australian- and overseas-qualified nurses are opportunities for new experiences, expectations of an opportunity to use a wider range of skills and expectations of job availability. For overseas-qualified nurses, the main reasons for staying

2 The DIAC was renamed the DIBP in September 2013, and this department was absorbed into the Department of Home Affairs in late December 2017. 
in the NT were a sense of professional independence and responsibility, income and the NT lifestyle. The main reasons for leaving the NT were further travel, career opportunities elsewhere, completion of employment contract, stressful work (burnout) and dissatisfaction with management. Australian-qualified nurses cited family and social networks (elsewhere) and burnout as their main reasons for leaving the NT.

Another workforce-specific study investigated the characteristics of overseas-born residents in the early childhood education and care (ECEC) workforce in the NT (Golebiowska \& Boyle, 2014). ${ }^{3}$ In the 2011 Census (ABS, 2011), overseas-born residents represented 27.5 per cent of the ECEC workforce in the NT, compared to 24 per cent in the 2006 Census. Asian-born residents represented the single largest share in the NT ECEC workforce after Australian-born residents, with their share having increased from 10.5 per cent to 15.7 per cent between the 2006 and 2011 censuses and remaining higher in the NT than in Australia as a whole (Golebiowska \& Boyle, 2014; ABS, 2011, 2016). This provides another illustration of the ongoing shift in countries of origin.

In contrast to overseas-qualified nurses who were skilled migrants, the majority of interviewed overseas-born ECEC workers (63 per cent) were family category migrants. All skilled interviewees ( 15 per cent) were dependent on their husbands' skilled visas. Workers with refugee backgrounds accounted for 11 per cent of interviewees, and the majority of the remaining 11 per cent were in non-visa categories (e.g. overseasborn children of Australian citizens). Regardless of immigration category, migration served to reunite or keep a family together.

People who move to Australia under the family migration category are often skilled and, per Golebiowska and Boyle's (2014) study, making an equally valuable economic contribution. All interviewees had post-school qualifications, and in some cases these were a level higher (e.g. a bachelor or diploma) than the minimum required to work in the ECEC sector in Australia (usually a Certificate III in Children's Services).

Due to a lack of formal work experience in the ECEC sector overseas (78 per cent of interviewees) and the majority having formal qualifications in areas other than ECEC, most interviewees were working in the ECEC

3 This study analysed unpublished 2006 and 2011 census statistics, immigration statistics from the DIAC and involved 27 face-to-face interviews with overseas-born residents employed at selected long day childcare centres in Darwin and Palmerston. 
for the first time. The lack of formal ECEC work experience overseas is likely because formalised childcare arrangements are not as well developed overseas as in Australia and looking after children is part of the assumed family duties of females. The key motivations for joining the ECEC workforce included a passion for working with children; prior experience of looking after children in family settings; finding the studies required to join the workforce interesting and enjoyable; suggestions from family, friends and Centrelink; and the awareness that as educators they can influence the development of young children (Golebiowska \& Boyle, 2014).

At the time of interviews in mid-2012, the ECEC workforce Australia wide was in the process of upskilling to meet the new regulations for minimum formal qualifications (a Certificate III in Children's Services). Over two-thirds (68 per cent) of interviewees had already met or exceeded the qualification requirement and 70 per cent were either interested in furthering their studies or already studying. A significant proportion of interviewees identified that although their English-language speaking and listening skills were high, they believed that their reading and writing skills were not sufficient to enable them to continue their studies at a higher level (Golebiowska \& Boyle, 2014).

Family ties and the NT lifestyle/climate were cited by interviewees as the two principal reasons for migration to and staying in the NT. A friendly and multicultural community and a small city ranked third in the reasons for migrating and second in the reasons for staying (ex aequo with overall work satisfaction). The third reason for staying was support from management ex aequo with good relationships with other staff. Importantly, 85 per cent of interviewees intended to live in the NT permanently or longer term, primarily for family reasons. As 81 per cent of interviewees anticipated working in the NT ECEC sector in the next 5-10 years, it can be surmised that nearly all stayers would remain employed in the ECEC industry for this period of time (Golebiowska \& Boyle, 2014).

Interviewees suggested that higher wages ( 85 per cent), more time to upgrade formal qualifications ( 48 per cent), better financial recognition of higher-level qualifications (22 per cent) and more flexible modes of formal training ( 22 per cent) would improve their employment experience. Importantly, 7 per cent of interviewees representing Asian and African countries noted that their prior learning should be better recognised 
by the Australian ECEC sector. Unsurprisingly, given their own roles as educators, all but one of these improvements relates exclusively to education. This suggests their genuine desire to pursue further education if it is accessible, appropriately recognised and suitably remunerated.

Suggestions as to how overseas-qualified professionals could be helped to remain in the NT long term were related to work and their settlement in the local community. Garnett et al. (2008) identified that providing an information package about Darwin and helping with securing affordable accommodation would facilitate settling in. Buergelt (2011) suggested that the challenges immigrants and employing organisation experience initially could be addressed by providing intensive training in English, Australian-specific professional terminology and Australian- or organisation-specific work culture.

Notwithstanding the shortages of skilled workers in Northern Australia, many take a long time to find a job that matches their professional qualifications and aspirations. High living expenses and absence of income push many immigrants to take any employment. Regardless of their job status in their home country, many migrants are compelled to engage in whatever work they find from cleaning to sales jobs to childcare to hospitality. Working in jobs that do not match their skills and are lower paid and of lower status than they had in their home location causes dissatisfaction that may result in migrants re-evaluating their initial migration decision and deciding to leave for a place where they can secure more appropriate employment (Buergelt, 2011). This is a longstanding issue for immigrants settled in the Darwin area (Haines, 2001) and is not unique to the NT (Tani, 2018).

\section{Observations from a Historical Study}

Vietnamese farmers are now an integral part of the horticulture industry in Darwin's hinterland. The story of the Vietnamese farming community is part of the local mythology caught up with images of 'boat people'. It is commonly believed that these refugees came from farming backgrounds, but this is incorrect. In 1980, the Federal Government and new NT Government entered into an agreement to take relatively large numbers of Vietnamese refugees from camps in Southeast Asia to create a Vietnamese 'community' in Darwin and increase the population. The criteria included good education, skills and urban background, 'young families' and precluded single unattached uneducated males (Haines, 2001, p. 11). 
Haines estimated that more than 1,000 Vietnamese arrived in Darwin in the early 1980s. However, by 1986, more than half had migrated interstate to find better employment opportunities than were available in Darwin (Haines, 2001, p. 60). The ones who stayed were more likely to have found employment and to have family support (Haines, 2001, p. 105).

Haines (2001) reported that there were 21 Vietnamese farmers in the Darwin region in 1995. These individuals often had little knowledge or experience of farming, but gravitated towards farming because speaking English was not a requirement and it provided a pragmatic solution to providing for their families (Haines, 2001, pp. 83-85). According to the 2011 Census (ABS, 2011), 883 people in the NT indicated that they had Vietnamese ancestry. Of these, 33.6 per cent were born in Australia. Most of those with Vietnamese ancestry lived in the Darwin region (85.2 per cent), the majority in the urban areas. Of these that were employed, 36.2 per cent worked in agriculture, forestry and fishing.

\section{International Students}

Skill shortages in the north could also be reduced by attracting and retaining other classes of immigrants, in particular, international students who can apply for permanent residence and add to the skill pool. The contribution of international students to the labour force is significant, especially in industries such as hospitality and retail trade that offer casual and parttime employment at times congruent with study demands. Education is now one of Australia's largest export industries. Hawthorne (2010, pp. 6, $10,29,30)$ observed that the majority of onshore immigrants are former international students:

This phenomenon of 'two-step' student migration is one proliferating world-wide ... The next challenge will be to keep them, in an increasingly competitive global environment where students have been prioritized for selection by multiple OECD countries ... Within this context, international students will become highly discerning education and migration consumersresearching global options to select the optimal study, migration and lifestyle 'package'. Multiple factors will inform their decisions, including the speed and certainty of selection, access to work rights and citizenship (for family as well as primary applicants), and the quality of employment outcomes. 
However, institutions in Northern Australia attract only a small percentage of international students coming to Australia. Overall, only 3 per cent of international students studying in Australia go to regional areas. In 2018, 10 per cent of the 26,789 international students studying in Australia were located in the NT (almost all in the Darwin area), while 7 per cent were in Townsville and 9 per cent in Cairns. Between 2017 and 2018, there have been small increases in the percentage studying in Darwin, but corresponding decreases in those studying in North Queensland (Department of Education and Training, 2019). Increasing the number of international student enrolments has been identified in a number of reports as a significant potential contributor to the economy, predominantly through student's fees, living costs and demand for services. To illustrate, in the NT in 2007-08, the presence of international students ${ }^{4}$ contributed 196 full-time jobs (54 in the education industry and 142 in other industries) (Access Economics, 2009, p. 8).This indicates that international education has a spillover effect on other sectors in the economy. International education (spending by onshore students) contributed A $\$ 38$ million to the NT economy in 2010-2011 and A $\$ 55$ million in 2014-15 (Australian Education International, 2012, 2015). International students also participate in the labour market and their contributions to local economies need to be better understood and appreciated by authorities. The focus of governments and educational institutions has largely been on attracting full-fee-paying international students, rather than their potential contributions to addressing skills shortages and how to retain them as permanent residents on completion of their studies. This requires a concerted and cooperative approach by the relevant state and territory governments that often do not focus on such regional issues.

\section{Family, Psychosocial, Social and Cultural Connectedness}

Migration decisions need to be seen in the context of individual life courses and lifespan processes. Strong family and community ties contribute to an immigrant's sense of stability and likelihood of staying in Australia.

4 International students at the tertiary study level, in ELICOS (now English Australia) and other non-award courses and schools. 
Analysis of the census data (see above) indicates that the majority of immigrants are in marital-type relationships, although lower proportions of those in Northern Australia are actually married.

It is recognised that migration places numerous stresses on families:

\begin{abstract}
These factors may take many years to resolve and include: changed economic status-either loss of status or better economic conditions that alter relationships; conflict and stress relating to having to re-establish themselves ... adapting to a different environment, language and culture ... loss of human and social capital ... lack of a sense of recognition, belonging and inclusion ... strict migration laws can erode traditional family structures, reduce family support structures and limit the connection between generations. (Queensland Government, 2011)
\end{abstract}

Further, migration has disproportionately negative impacts on women, particularly in terms of family incomes, loss of family and social support, and discrimination (Queensland Government, 2011).

However, if partners and children are settled and feel welcome, migrants are more likely to intend to stay in a regional location (Griffiths et al. 2010). Khoo et al. (2013) had similar findings, but warned that:

While most family migrants already contribute to their families' welfare and many also contribute to the economy and the community, some of them have had difficulty in finding employment or have expressed low satisfaction with their jobs and financial situation. There is scope for improving employment outcomes of family migrants to increase their economic contributions and improve their families' economic welfare and their own level of life satisfaction. (p. 92)

Migration entails substantial mental, emotional and financial investment, and is highly risky and uncertain. Not mastering the mental, emotional and physical preparation and integration processes can lead to psychological and physical health issues, isolation, alienation and homesickness; relationship issues with partners children and extended family; work performance issues; financial hardship; and, ultimately, antagonism towards locals and their culture. All of these can lead to migrants leaving. However, these negative outcomes can be prevented and reduced, and positive outcomes facilitated by assisting migrants to successfully adapt to their new environment. Buergelt $(2011,2012)$ showed that success in moving between cultures is determined by the mindset and capabilities 
of people migrating and by a set of contextual factors in the locations of origin and destination. High turnover rates are partly due to migrants and their families experiencing problems adapting to their new work and living environments, but also due to employers and government poorly selecting, preparing and supporting migrants.

\section{Place Characteristics}

A wide variety of natural, cultural and social place characteristics play a critical role in attracting and retaining migrants. While immigration policies are focused on attracting immigrants to regional Australia, retention appears to be a problem with a significant percentage of immigrants moving to capital cities once they have met the visa conditions. Several characteristics have been identified as deterring migrants from choosing to move to and stay in Northern Australia. Anwar and Prideaux (2005) hypothesised that climate extremes and remoteness from (southern) population centres cause high rates of population turnover among immigrants once their minimum duration of stay under their migration program is completed. However, Taylor et al. (2014) provided a more positive view with lifestyle and amenity noted as significant pull factors.

Other research points to factors that may have a mitigating effect on a decision to leave once contractual visa obligations have been met. Griffiths et al. (2010) found that 70 per cent of survey respondents were positive about their chosen regional area, citing the quality of life in regional environments and smaller communities, with many preferring it to larger cities. Immigrants from South and Southeast Asia appreciated the hot and humid climatic conditions which are comparable to their home country and the relative proximity of Northern Australian cities to their country of origin. However, 30 per cent of respondents were dissatisfied with the living conditions. They expressed concerns about climate, high costs of living (especially the cost of housing) and the low standard of public and community facilities including schools, housing and transport-all were disincentives to them staying in Northern Australia.

Taylor et al. (2014) reported very high retention rates for regional skilled migrants in the NT (90 per cent) and even higher rates for migrants on specific visas like the Regional Sponsored Migration Scheme (RSMS) visa (93 per cent), with more than half of RSMS respondents stating that they intended never to leave the NT. 'This indicates that, at worst, skilled 
migrants are no less likely to leave the NT ... than other residents and at best that the majority might remain there for the longer term' (Taylor et al., 2014, p. 15).

Research undertaken for Multicultural Affairs Queensland and Welcoming Australia suggested a number of essential strategies for retaining immigrants in regional communities (van Kooy et al., 2019), in particular, the importance of locally driven coordination, consultation and planning at the local/regional council level; consultation with migrant organisations and local Indigenous communities; accessible, affordable housing, transport and culturally appropriate services; and creating a culture of welcome in receiving communities.

\section{Summary and Conclusions}

Small resident populations and skill shortages limit the economic development of Northern Australia. Since white settlement, Australian states have relied on immigration to build their economies and labour forces. Nevertheless, Northern Australia attracts only a very small percentage of the total immigrant intake to Australia. The research presented in this chapter provides evidence that permanent and temporary immigrants to Northern Australia contribute to the economy and labour force, particularly in the services areas. These immigrants are also more likely than migrants elsewhere in Australia to settle permanently in the north with their families and so build the population. In light of the higher turnover of overseas-born workers compared to Australian-born workers, continued research into attraction and retention factors for the former is needed, including in sectors of the economy other than health services and ECEC. Immigration, especially from the regions close to Northern Australia (Southeast Asia, the Philippines, India and China), could be a significant contributor to growing both the working population and stable and vibrant communities in Northern Australia. Successfully attracting and retaining immigrants requires understanding and addressing the challenges that they and their families face in obtaining employment that is appropriate to their skills and qualifications, housing, education, transport and community connections.

Notwithstanding the benefits they bring to the community and economy, immigrants face many challenges in migration to and settlement in Northern Australia. These include lack of skills recognition, adaptation 
to the local labour force including assistance with job search, and orientation to local organisational cultures. The research reported in this chapter has identified a number of strategies to facilitate successful employment. These include a more streamlined qualifications translation process, recognition of experience, profession specific English language programs and employment-orientation programs that assist immigrants in understanding local organisational and social cultures. On the other side, managers need training and support in selection, orientation and integration of immigrants from very diverse social, educational and linguistic backgrounds into work and organisational cultures.

Migrating to and settling into a community is often a family decision. Accordingly, creating community and organisational culture and structures to support immigrants and their families before, during and after they move to Northern Australia is vital in ensuring that families feel welcome and choose to settle and stay in Northern Australia. Employment opportunities for partners are important, as is recognition of the educational and language needs of children from different linguistic and social backgrounds. Culturally appropriate health and community services including those directed towards families are particularly important and require additional investment that may be hard to justify for very small populations. While these challenges exist throughout Australia, they are particular important in the small and geographically isolated communities in Northern Australia.

Orientation to the destination culture, society and economy is important for all immigrants. Northern Australia is home to large numbers of Indigenous Australians, many of whom live in their traditional communities. Gaining an understanding and appreciation of their culture and the impact that immigration and development plans have on their societies is particularly important for all migrants living and working in the north.

\section{References}

Access Economics. (2009, April). The Australian education sector and the economic contribution of international students. Retrieved from globalhighered.files. wordpress.com/2009/04/theaustralian educationsectorandtheeconomic contributionofinternationalstudents-2461.pdf

Anwar, S. \& Prideaux, B. (2005). Regional economic growth: An evaluation of the NT. Economic Papers, 24(3), 194-214. 
Australian Bureau of Statistics (ABS). (2011). 2011 Census of population and housing. Available from www.abs.gov.au

Australian Bureau of Statistics (ABS). (2016). 2016 Census of population and housing. Available from www.abs.gov.au

Australian Education International. (2012, April). International education snapshot. Retrieved from internationaleducation.gov.au/International-network/ Australia/InternationalStrategy/IEAC2/Consultation(IEAC)/Documents/ DataSnapshot.pdf

Australian Education International. (2015, November). Export income to Australia from international education activity in 2014-2015. Retrieved from international education.gov.au/research/Research-Snapshots/Documents/Export\%20Income \%20FY2014-5.pdf

Boese, M. (2015). The roles of employers in the regional settlement of recently arrived migrants and refugees. Journal of Sociology, 51(2), 401-416. doi.org/ $10.1177 / 1440783314544994$

Buergelt, P. T. (2011). Contemporary migration between developed countries: Transformation processes towards actualising authentic selves and lives (unpublished doctoral thesis). Massey University, New Zealand.

Buergelt, P. T. (2012, March). Migration motives and challenges: Implications for countries of origin and settlement. Keynote address at the Intergovernmental Consultations on Migration, Asylum and Refugees (IGC) Chair's Theme Workshop on Motives for Migration, IGC, Geneva, Switzerland.

Department of Education and Training. (2019, February). International students studying in regional areas. Retrieved from internationaleducation.gov.au/ research/Research-Snapshots/Documents/Location\%20of\%20International \%20Students\%20in\%202018.pdf

Department of Immigration and Border Protection (DIBP). (2013a). Migration to Australia's states and territories, 2012-13. Retrieved from www.homeaffairs.gov. $\mathrm{au} /$ research-and-stats/files/migration-australia-state-territories-2012-13.pdf

Department of Immigration and Border Protection (DIBP). (2013b). Subclass 457 State/Territory summary report, 2012-13 to 30 June 2013. Retrieved from www.homeaffairs.gov.au/research-and-stats/files/state-territory-summary2012-13-to-30-june-2013.pdf

Department of Immigration and Border Protection (DIBP). (2014). State and territory migration summary, 30 June 2014. Retrieved from www.home affairs.gov.au/research-and-stats/files/state-territory-migration-summaryjune-2014.pdf 
Department of Immigration and Citizenship (DIAC). (2011). Subclass 457 Statel Territory summary report, 2010-11 to 30 June 2011. Retrieved from www.home affairs.gov.au/research-and-stats/files/457-stats-state-territory-jun11.pdf

Flanagan, J. (2007). Dropped from the moon-the settlement experiences of refugee communities in Tasmania. Retrieved from www.anglicare-tas.org.au/research/ dropped_from_the_moon/

Garnett, S., Coe, K., Golebiowska, K., Walsh, H., Zander, K., Guthridge, S., Li, S. Q. \& Malyon, R. (2008). Attracting and keeping nursing professionals in an environment of chronic labour shortage. Darwin, NT: Charles Darwin University Press.

Golebiowska, K. (2009). Country of origin and labour market participation of the overseas-born in the NT (Research Brief Issue 2009039). Population Studies Group, School for Social and Policy Research, Charles Darwin University. Retrieved from www.cdu.edu.au/sites/default/files/research-brief-2009-39.pdf

Golebiowska, K. (2015). Are peripheral regions benefiting from national policies aimed at attracting skilled migrants? Case study of the Northern Territory of Australia. Journal of International Migration and Integration 17, 947-971. doi.org/10.1007/s12134-015-0431-3

Golebiowska, K. \& Boyle, A. (2014). Professional integration and belonging of the immigrant-born early childhood education and care (ECEC) workers in Darwin, Northern Territory, Australia. International Journal of Organisational Diversity, 13(2), 1-17.

Griffiths, J., Laffan, W. \& Jones, A. (2010, June). Factors that influence skilled migrants locating in regional areas. Final report. Retrieved from www.dss.gov. $\mathrm{au} /$ sites/default/files/documents/01_2014/factors-influence-skilled-migrantslocating-regional-areas.pdf

Haines, T. K. (2001). 'Replacing Vietnam'. A longitudinal study of a refugee population in isolation: The Vietnamese of Darwin (unpublished doctoral thesis). University of Queensland, Brisbane, Qld.

Hawthorne, L. (2010). How valuable is 'two-step migration'? Labour market outcomes for international student migrants to Australia. Asian and Pacific Migration Journal, 19(1), 5-36. doi.org/10.1177/011719681001900102

Hugo, G. (2008). Australia's state-specific and regional migration scheme: An assessment of its impacts in South Australia. Journal of International Migration and Integration, 9(2), 125-145. doi.org/10.1007/s12134-008-0055-y 
Joint Select Committee on Northern Australia. (2014). Pivot North: Inquiry into the development of Northern Australia_Final report. Canberra, ACT: Australian Government. Retrieved from www.aph.gov.au/Parliamentary_Business/ Committees/Joint/Former_Committees/Northern_Australia/Inquiry_into _the_Development_of_Northern_Australia/Tabled_Reports

Khoo, S.-E., McDonald, P. \& Edgar, B. (2013, April). Contribution of family migration to Australia. Report to the Department of Immigration and Citizenship.

McDonald, B., Gifford, S., Webster, K., Wiseman, J. \& Casey, S. (2008). Refugee resettlement in regional and rural Victoria: Impacts and policy issues. Retrieved from library.bsl.org.au/jspui/bitstream/1/977/1/RefugeeResettlement_Report_ Mar08.pdf

Piper, M. \& Associates. (2007, March). Shepparton regional humanitarian settlement pilot. Summary report of an evaluation undertaken by Margaret Piper and Associates for the Department of Immigration and Citizenship.

Piper, M. \& Associates. (2008, November). Regional humanitarian settlement pilot Mount Gambier. Report of an evaluation undertaken by Margaret Piper and Associates for the Department of Immigration and Citizenship.

Piper, M. \& Associates. (2009, January). Regional humanitarian settlement pilot Ballarat. Report of an evaluation undertaken by Margaret Piper and Associates for the Department of Immigration and Citizenship.

Queensland Government. (2011). Supporting information: Understanding the effects of migration and settlement. Retrieved from www.qld.gov.au/web/ community-engagement/guides-factsheets/cald-communities/introduction/ understanding-migration-effects.html

Tani, M. (2018, 8 February). Australia's jobs and migration policies are not making the best use of qualified migrants. The Conversation. Retrieved from theconversation.com/australias-jobs-and-migration-policies-are-not-makingthe-best-use-of-qualified-migrants-90944

Taylor, A. J., Bell, L. \& Gerritsen, R. (2014). Benefits of skilled migration programs for regional Australia: Perspectives from the Northern Territory. Journal of Economic and Social Policy, 16(1), article 3.

Taylor, J. \& Stanovic, D. (2005). Refugees and regional settlement: Balancing priorities. Retrieved from library.bsl.org.au/jspui/bitstream/1/6212/1/regional_ refugee_summary.pdf

van Kooy, J., Wickes, R. \& Ali, A. (2019). Welcoming regions. Retrieved from welcomingcities.org.au/wp-content/uploads/2019/03/WelcomingRegions_ Summary.pdf 
This text is taken from Leading from the North: Rethinking Northern Australia Development, edited by Ruth Wallace, Sharon Harwood, Rolf Gerritsen, Bruce Prideaux, Tom Brewer, Linda Rosenman and Allan Dale, published 2021 by ANU Press, The Australian National University, Canberra, Australia.

doi.org/10.22459/LN.2021.11 